\title{
De openbare accountant en zijn verantwoordelijkheid ter zake van belastingen en ten opzichte van de belastingdienst
}

\section{M. P. Busio}

In dit artikel wil ik ingaan op de vraag of, in hoeverre en op welke wijze de openbare accountant (hierna ook te noemen de accountant) tegenover de belastingdienst en het maatschappelijk verkeer verantwoordelijkheid draagt ter zake van belastingen.

Voor beantwoording van deze vraag maak ik achtereenvolgens het volgende onderscheid:

1 het verzorgen van aangiften vennootschapsbelasting;

2 de belastingen in de jaarrekening in het kader van de jaarrekeningcontrole;

3 het constateren van belastingfraude.

\section{Het verzorgen van aangiften vennootschapsbelasting}

\subsection{Inleiding}

Kernproblematiek is het volgende.

1 Welke verantwoordelijkheid heeft de openbare accountant ten aanzien van aangiften vennootschapsbelasting die door hem verzorgd zijn, e.e.a. bezien vanuit de GBR?

2 In hoeverre wordt deze verantwoordelijkheid beïnvloed door het feit dat er al dan niet sprake is van een jaarrekening waarop accountantscontrole is toegepast en die voorzien is van een goedkeurende accountantsverklaring?

\subsection{Aangifte vennootschapsbelasting en GBR}

De aangifte vennootschapsbelasting (met inbegrip van de daarin opgenomen fiscale vermogens- en resultaatsopstelling) is een verantwoording in de zin van de GBR.

Voldaan wordt immers aan de eisen die in de Richtlijnen Controle gesteld worden aan een verantwoording, hetgeen recentelijk is bevestigd in de uitspraak van de Raad van Beroep, JT 198812.

Vanuit de GBR hebben dan ook de artikelen 6 en $12 \mathrm{t} / \mathrm{m} 14$ bijzondere betekenis voor het dragen van verantwoordelijkheid door de accountant ten aanzien van de door hem verzorgde belastingaangiften.

Indien een openbare accountant de aangifte vennootschapsbelasting verzorgt, is zijn verantwoordelijkheid gekoppeld aan de wijze waarop dit naar de fiscus toe, dat wil zeggen naar buiten toe, blijkt:

1 De bij de belastingaangifte gevoegde fiscale jaarstukken dragen naam en logo van het accountantskantoor.

2 De belastingaangifte vermeldt de naam van het accountantskantoor dat de aangifte verzorgd heeft, omdat hiermee voldaan wordt aan de eis van de belastingsdienst ter zake van het gebruik maken door belastingplichtige van de

C. M. P. Busio

Registeraccountant, Rijksaccountantsdienst, Hoofd

Bureau RAD te Zeist. 
uitstelregeling voor accountants (en belastingconsulenten).

3 De bijgevoegde fiscale jaarstukken zijn weliswaar gesteld op blanco papier, maar de papiersoort, typetechniek, enzovoort zijn kenmerkend voor het desbetreffende accountantskantoor.

4 Op geen enkele wijze blijkt uit de belastingaangifte de betrokkenheid van de accountant ten aanzien van die aangifte.

Uitsluitend in de situaties drie en vier is er sprake van dat er geen indruk wordt gewekt, dat de belastingaangifte van de accountant afkomstig is.

In de eerste twee genoemde situaties moet de accountant zich bewust zijn van artikel 6 GBR:

'De registeraccountant die een stuk, inhoudende een niet door of mede door hem afgelegde verantwoording afgeeft of doet afgeven, zodanig dat de indruk wordt gewekt dat het van hem afkomstig is, wordt geacht beroepshalve de getrouwheid van die verantwoording onderzocht te hebben, tenzij het tegendeel blijkt'.

Omdat de accountant in het algemeen niet de opdracht krijgt de aangifte vennootschapsbelasting op getrouwheid te controleren, dient hij het vorenbedoelde tegendeel te laten blijken door op ieder zelfstandig deel van de belastingaangifte, dus ook op de eventueel toegevoegde fiscale jaarstukken, de in artikel 6 GBR voorgeschreven bewoordingen te vermelden: 'geen onderzoek naar de getrouwheid ingesteld', 'geen accountantscontrole toegepast', dan wel 'niet gecontroleerd'.

Als het hiervorenbedoelde tegendeel niet blijkt, wordt de betreffende accountant op grond van artikel 13, lid 4 GBR geacht een goedkeurende verklaring zonder voorbehoud bij die belastingaangifte te hebben afgegeven.

Ter aanvulling zij nog het volgend opgemerkt.

Hoewel de drie in artikel 6 GBR genoemde bewoordingen een gelijke strekking hebben, verdient het aanbeveling de bewoording 'geen onderzoek naar de getrouwheid ingesteld' toe te passen.
De bewoording 'niet gecontroleerd' dient vermeden te worden, omdat dit de onjuiste indruk zou kunnen wekken, dat de accountant de cijfers in de fiscale jaarstukken in het geheel niet heeft gecontroleerd.

Voorts verdient nog het volgende de aandacht. Weliswaar geldt dat belastingplichtige primair zelf verantwoordelijk is voor de volledigheid en de juistheid van de gedane belastingaangifte; dit betekent evenwel niet dat de accountant geen enkele verantwoordelijkheid draagt voor de cijfers in en de toereikendheid van de aangifte.

De accountant die een belastingaangifte verzorgt, is op grond van artikel 11 GBR gebonden aan een deugdelijke grondslag voor die arbeid, ook als hij artikel 6 GBR toepast.

$\mathrm{Hij}$ is er dan ook voor verantwoordelijk dat de toegepaste grondslagen voor de fiscale vermogensen winstopstelling voldoen aan goed koopmansgebruik ex artikel 9 Wet IB 1964 en dat deze consistent zijn toegepast.

Voorts geldt dat hij - als hij artikel 6 GBR toepast minimaal een uitgebreide cijferbeoordeling op de jaarcijfers (ook in relatie tot voorgaande jaren) moet toepassen om de plausibiliteit van de belastingaangifte en het ontbreken van materiële fouten erin te beoordelen.

\subsection{Aangifte Vennootschapsbelasting en jaarre- keningcontrole}

Ter beantwoording van de vraag in hoeverre het bij het verzorgen van de aangifte vennootschapsbelasting door de accountant een rol speelt of er sprake is geweest van jaarrekeningcontrole en van het bij die jaarrekening afgeven van een goedkeurende accountantsverklaring moet onderscheid gemaakt worden tussen enerzijds de juistheid en volledigheid van de jaarrekening en anderzijds de toereikendheid ervan.

Met juistheid en volledigheid wordt bedoeld dat alle cijfers in de jaarrekening tot feiten zijn terug te voeren, respectievelijk dat alle feiten in de jaarrekening hun weerslag hebben gevonden.

Met toereikendheid wordt bedoeld dat (onder meer) de toegepaste grondslagen voor waardering van activa en passiva en voor resultaatsbepaling in overeenstemming zijn met de wettelijke bepalingen van Titel 8 Boek 2 BW. 


\section{MAB}

De fiscus is als gebruiker van de accountantsverklaring bij een jaarrekening die bij een aangifte vennootschapsbelasting is gevoegd, bekend met het feit dat de grondslagen voor de fiscale vermogens- en winstbepaling kunnen, dan wel moeten afwijken van de grondslagen die in de (commerciële) jaarrekening worden gehanteerd. Voor zover de goedkeurende verklaring betrekking heeft op de balans in de commerciële jaarrekening heeft deze voor de fiscus slechts betrekkelijke betekenis voor zover het de waarderingsgrondslagen betreft.

Voor zover de goedkeurende verklaring betrekking heeft op de juiste en volledige weergave van de feiten in de jaarrekening heeft deze verklaring wezenlijke betekenis voor de fiscus. Zo mag en zal de fiscus ervan uitgaan dat bijvoorbeeld de opbrengstenverantwoording volledig is.

Hierbij zal de fiscus er mee rekening moeten houden dat die juistheid en volledigheid in de jaarrekening enerzijds onderhevig is aan toleranties, anderzijds aan het axiomatisch voorbehoud:

$1 \mathrm{Er}$ kunnen en zullen verschillen in aanvaardbare toleranties zijn tussen de jaarrekening enerzijds en de aangifte vennootschapbelasting anderzijds. Dit hangt samen met het feit dat beide verantwoordingen weliswaar aan de eraan te stellen eisen moeten voldoen, maar dat die eisen ten opzichte van elkaar verschillen.

2 De goedkeurende verklaring betekent niet dat er geen fouten of omissies in de jaarrekening zitten. Voor zover deze voor de accountant onder het axiomatisch voorbehoud vallen is de accountant er niet voor verantwoordelijk.

De fiscus dient hier enerzijds rekening mee te houden en anderzijds zo mogelijk dit voorbehoud zelf af te dekken (bijvoorbeeld door het gebruik maken van inlichtingen bij derden op grond van artikel 49 AWR).

Voorts dient het volgende gememoreerd te worden. Indien de aangifte vennootschapsbelasting vergezeld gaat van de balans en winst- en verliesrekening uit de (commerciële) jaarrekening dan mag de fiscus er van uitgaan dat de accountant bij deze stukken een goedkeurende verklaring heeft afgegeven, indien het tegendeel niet blijkt.

\section{Belastingen in de jaarrekening}

\subsection{Verantwoordelijkheid}

Als algemene stelling geldt dat iedere belastingplichtige zijn belastingaangifte zodanig moet doen, dat hij daarin waarheidsgetrouw alle feiten, gegevens, omstandigheden en het financiële effect daarvan verwerkt en vermeldt, voor zover deze van belang zijn voor een juiste en tijdige belastingheffing.

ledere ondernemer is er als belastingplichtige dan ook verantwoordelijk voor dat hij zijn belastingaangiften volledig en juist invult, tijdig indient en de verschuldige belasting tijdig afdraagt.

De in de belastingaangifte vermelde belastingbedragen (omzet- en loonbelasting) en de resultante van de in de aangifte vermelde feiten (vennootschapsbelasting) verschijnen in de jaarrekening als kostenpost en/of (deels) als balanspost.

Uit dien hoofde behoort het tot de taak van de openbare accountant om als onderdeel van zijn jaarrekeningcontrole de volledige en juiste verwerking van de belastingen in de jaarrekening en de daaraan ten grondslag liggende administratie vast te stellen.

Door zijn goedkeurende verklaring bij de jaarrekening brengt hij tot uitdrukking en draagt er daardoor verantwoordelijkheid voor, dat de belastingen juist en volledig in de jaarrekeningen zijn verwerkt, een en ander bınnen de toleranties die gelden voor het getrouwe beeld dat de jaarrekening moet geven.

Hierna wordt ingegaan op de invloed die vorenstaande stelling ter zake van de verantwoordelijkheid van de accountant voor belastingen heeft op zijn taakvervulling, te onderscheiden naar omzetbelasting, loonbelasting en vennootschapsbelasting.

\subsection{Omzetbelasting}

De noodzaak voor de accountant om de omzetbelasting in de jaarrekeningcontrole te betrekken blijkt onder meer uit het feit, dat

1 indien de ondernemer de aan hem in rekening gebrachte omzetbelasting niet verrekent, zijn kosten te hoog zullen zijn (bijvoorbeeld als gevolg van boekingsfouten); 


\section{MAB}

2 indien de ondernemer niet-verrekenbare omzetbelasting toch in aftrek brengt op zijn belastingaangifte, hij de fiscus tekort doet;

3 indien de ondernemer ter zake van geleverde prestaties een te laag OB-tarief dan wel ten onrechte geen omzetbelasting in rekening brengt en/of afdraagt, hij de fiscus tekort doet.

In het kader van de beoordeling van de administratieve organisatie en de hierin begrepen maatregelen van interne controle dient de accountant ten behoeve van zijn jaarrekeningcontrole kennis te nemen van de boekingsvoorschriften ter zake van de verschuldigde en de te verrekenen omzetbelasting en van de instructies die gegeven zijn ter bepaling van bijzondere situaties, zoals toepassing hoog, laag of nultarief, van het Besluit Uitsluiting Aftrek en van de toepassing van artikel 11 Wet OB (vrijstelling van omzetbelasting), artikelen 18 en 23 Wet $O B$ (heffing ter zake van invoer), artikel 29 Wet OB (oninbare debiteuren en 'oude' crediteuren) en artikel 11 Uitvoeringsbeschikking OB (gemengde prestaties).

Voorts zal hij moeten vaststellen dat op de uitvoering van deze boekingsvoorschriften intern controle wordt uitgeoefend.

Daarnaast zal hij zelf enerzijds steekproefsgewijs de vooraftrek op volledigheid en juistheid moeten toetsen en anderzijds, door middel van steekproefsgewijze toetsing van toepassing van het juiste tarief en in samenhang met totaalcontroles, de volledigheid van de verschuldigde omzetbelasting moeten beoordelen.

Tevens moet de accountant vaststellen dat de aangiften omzetbelasting in overeenstemming zijn met het bedrijfsgebeuren en de neerslag daarvan in de administratie en dat deze belastingaangiften en - niet te vergeten - de afdrachten van de omzetbelasting die voldaan moet worden, volledig en tijdig plaatsvinden, onder andere door beoordeling van de regelmaat der betalingen en door afloopcontrole.

In zijn controle zal hij mede betrekken de uitkomsten van voorgaande controles omzetbelasting door de belastingdienst en zijn eigen ervaringen uit het verleden.

Uiteraard zal de diepgang van de controle door de accountant mede bepaald worden door het belang dat de omzetbelasting heeft voor het jaarrekeningbeeld en door risico-analyse inzake de kans op (belangrijke) fouten.

\subsection{Loonbelasting}

Voor de loonbelasting geldt dat de ondernemer er voor verantwoordelijk is dat hij ten aanzien van de door hem gedane loonbetalingen de juiste en volledige inhoudingen pleegt - eventueel na correctie brutering als het om netto beloningen gaat deze aangeeft en vervolgens tijdig afdraagt.

Voor de beoordeling of de uit de looncijfers voortvloeiende loonbelastingschuld volledig in de jaarrekening is opgenomen, zal de accountant in het kader van zijn jaarrekeningcontrole de volgende controlehandelingen moeten verrichten.

Ten eerste moet hij de administratieve organisatie rondom het personeel beoordelen: functiescheiding tussen aanname en ontslag van personeel, vaststellen van de arbeidsbeloning (CAO-gegevens, arbeidscontracten, notulen), vaststellen en registratie van de arbeidsprestaties, loonberekening. loonbetaling en registratie van de arbeidskosten.

Voorts zal hij moeten vaststellen dat het loonbestand juist en volledig is.

Bijzondere aandacht heeft de accountant voor de omrekening van brutoloon naar nettoloon, ofwel voor de juiste tabel-/tariefstoepassing inclusief het tarief voor bijzondere beloningen.

Of de omrekening op de juiste wijze geschiedt, zal hij toetsen door onder meer cijferbeoordeling op individuele bruto-netto-berekeningen een op ontwikkelingen in de tijd en door een aantal proefgevallen zelf te berekenen. Het verdient hierbij aanbeveling om naast een willekeurige steekproef ook een kritische steekproef te nemen en wel gericht op de loonadministrateur, personeel dat betrokken is bij de programmering van de loonregistratie en op de directie.

Uiteraard zal de accountant toetsen dat er aansluiting bestaat tussen de loonkostencijfers in de resultatenrekening enerzijds en die in de grootboekrekening anderzijds. Tevens stelt hij overeenstemming vast tussen de loonkostencijfers en de gegevens in de verzamelloonstaat. 
Voorts zal hij cijferbeoordeling toepassen op de loon- en salariskosten en de ingehouden loonbelasting. Hierbij vindt vergelijking plaats in de ontwikkeling in het jaar en vergelijking met overeenkomstige perioden in het voorgaande jaar.

Daarnaast zal de accountant in het bijzonder aandacht hebben voor instructies inzake de uitvoering van en het toezicht op de toepassing van artikel 11 Wet LB: 'Tot het loon behoren niet .....'.

Met name zal hij aandacht moeten hebben voor het aspect 'bovenmatige kostenvergoedingen'. Immers de hieruit voortvloeiende verschuldigde loonbelasting komt in het algemeen voor rekening van de ondernemer en vormt voor hem dus een kostenpost en leidt tot een hogere loonbelastingschuld.

De controle van de accountant is vooral gericht op procedures voor vaststelling en toetsing van de aanvaardbaarheid van de hoogte van kostenvergoedingen, aangevuld met steekproefsgewijze toetsing.

Indien de accountant op objectieve gronden tot de conclusie komt dat er bovenmatige kostenvergoedingen zijn betaald, dient hij de bedrijfsleiding hiervan op de hoogte te stellen en er zorg voor te dragen dat de acute loonbelastingschuld verhoogd wordt met de te dier zake verschuldigde loonbelasting.

Bij ondernemingen die in het kader van de Wet Ketenaansprakelijkheid hoofdelijk aansprakelijk gesteld kunnen worden voor de door een aannemer verschuldigde belasting, dient de accountant vast te stellen in hoeverre er per balansdatum claims van de belastingdienst te dier zake verwacht kunnen worden.

De accountant zal er vervolgens op moeten letten dat de gedane belastingaangiften in overeenstemming zijn met de feiten en de weergave daarvan in de administratie en dat de aangiften en afdrachten tijdig zijn geschied.

Ook hier zal de accountant ten behoeve van de invulling van zijn controle- en werkprogramma zich enerzijds laten leiden door materialiteit (aantal personeelsleden) en audit risk (zoals deze onder andere voortvloeit uit de typologie van het bedrijf, zoals aannemer of horeca, en uit bijzon- dere loon- en kostenregelingen) en anderzijds door ervaringen uit het verleden en uitkomsten van vorige loonbelastingcontroles.

\subsection{Vennootschapsbelasting}

\subsubsection{Inleiding}

In het kader van de jaarrekeningcontrole moet de accountant zich ervan vergewissen dat alle fiscale gevolgen van het bedrijfsgebeuren naar behoren in de jaarrekening zijn verwerkt. Dit geldt ook voor de belasting naar de winst, zowel de acute als de latente.

Deze eis vloeit voort uit Boek 2 BW, titel 8, waarin onder meer geregeld is, dat

- afzonderlijk vermelding dient plaats te vinden van de voorziening voor belastingverplichtingen die na het boekjaar kunnen ontstaan, maar hun ontstaansgrond vinden in het lopende, dan wel een vorig boekjaar (latente belasting, artikel 374 , lid 4, letter a);

- afzonderlijke vermelding moet plaatsvinden van de belasting die op het resultaat drukt (artikel 377 , lid 1, letters a en b) en van de ter zake hiervan ontstane belastingschuld (artikel 375 , lid 1 , letter h).

Vorenstaande houdt in dat de accountant zich zelfstandig een oordeel moet vormen met betrekking tot de aanvaardbaarheid van de berekende belastbare winst en de daaruit voortvloeiende belastingverplichting.

Hierbij dient wel bedacht te worden dat de accountant de aanvaardbaarheid en de juiste toepassing van de waarderingsgrondslagen en grondslagen voor winstbepaling - voor zover deze in fiscale zin mogen, respectievelijk moeten afwijken ten opzichte van de jaarrekening - primair beoordeelt op plausibiliteit met inachtneming van de nodige toleranties.

\subsubsection{Acute vennootschapsbelasting}

De belastingschuld als balanspost ter zake van de belasting naar de winst, in Nederland de vennootschapsbelasting, komt in beginsel als volgt tot stand: 


\section{MAB}

Schuld begin boekjaar

Verschuldigde belasting over het belast-

bare bedrag van het lopende boekjaar

Gedane belastingbetalingen

Schuld einde boekjaar

De accountant zal de schuld aan het begin van het boekjaar toetsen aan de hand van de ontvangen belastingaanslagen en de gedane belastingaangiften over het afgelopen jaar resp. afgelopen jaren, rekening houdend met de in voorgaande jaren reeds gedane betalingen.

De gedane belastingbetalingen kan hij toetsen door positieve controle op de betalingen, eventueel aangevuld met controle op de strookjes van de acceptgirokaarten waarop het tot een bepaalde datum betaalde bedrag staat vermeld.

N.B. De invloed van investeringspremies blijft in dit kader buiten beschouwing.

Meer problemen heeft de accountant bij de beoordeling van de belasting die op de winst van het boekjaar drukt. Hiervoor geeft het commercieel resultaat vóór belastingen slechts een indicatie. Bepalend voor de effectieve belastingdruk is immers het belastbare bedrag.

De effectieve belastingdruk wijkt af van het nominale belastingpercentage door het bestaan van permanente verschillen tussen fiscale winst en commerciële winst, zoals fiscaal vrijgestelde baten (deelnemingsvrijstelling), door voordelen verkregen door het prijsgeven van niet voor verwezenlijking vatbare rechten door schuldeisers, door fiscaal niet aftrekbare kosten (zoals ter zake van buitenlandse deelnemingen, giften, commissarissenbeloning) en door fiscale faciliteiten welke leiden tot een reductie van belastingschuld (voorraad-en vermogensaftrek).

De accountant zal zich dan ook zelfstandig een oordeel moeten vormen over de over een boekjaar verschuldigde belasting naar de winst.

Aangezien het ook hier gaat om een getrouw beeld is geen $100 \%$ juistheid vereist.

In een situatie van continuïteit en winstgevendheid zal de accountant dan ook in de eerste plaats gebruik maken van cijferbeoordeling: de werkelijk verschuldigde belasting over boekjaren in het verleden gerelateerd aan het (commercieel) resultaat vóór belastingen is indicatief als ervaringspercentage voor de belastingdruk in het lopend boekjaar (effectieve belastingdruk).

Omdat een bedrijf in de praktijk pas (lang) na het tijdstip van afsluiten van de jaarrekeningcontrole de belastingaangifte opstelt c.q. laat opstellen, staat de accountant weinig ander gereedschap ten dienste dan

a het ervaringspercentage,

b beoordeling van de verdeling door de onderneming van de belasting op het bedrijfsresultaat in acute en latente belasting (na correctie voor vrijgestelde winsten).

Wel zal hij nog aandacht hebben voor het volgende:

- in hoeverre is de onderneming voornemens de grondslagen voor fiscale vermogens- en resultaatsbepaling te wijzigen ten opzichte van een vorig jaar?

- In hoeverre is te verwachten dat bepaalde belastingfaciliteiten een afwijkende invloed hebben op het beeld door wel respectievelijk geen ruimere toepassing ervan?

Of hiervan sprake zal zijn en in hoeverre dit invloed zal hebben, zal de accountant moeten bespreken met de directie en de belastingadviseur van het bedrijf. Zonodig zal hij bepaalde standpunten laten toetsen door het zelf inschakelen van een belastingdeskundige.

Bijzondere aandacht zal de accountant voorts hebben voor de uitkomsten van belastingcontroles - te weten de controlerapporten en de daarop gebaseerde belastingaanslagen - en voor lopende geschillen met de fiscus.

\subsubsection{Latente belastingverplichting}

Belastinglatenties in de jaarrekening worden veroorzaakt door verschillen in waardering van activa en/of passiva in de fiscale vermogensopstelling enerzijds en in de jaarrekening anderzijds, hieronder mede te begrijpen het gebruik maken van de fiscale faciliteit tot het vormen van fiscale reserves op grond van de artikelen 13 en 14 Wet 


\section{MAB}

IB 1964 en de mogelijkheid van verliescompensatie.

Belastinglatenties zijn het gevolg van tijdelijke verschillen in belastingheffing en zijn nader te onderscheiden in:

1 passieve belastinglatenties, een vorm van voorwaardelijke belastingverplichting,

2 actieve belastinglatenties, een vorm van voorwaardelijke belastingvordering.

De accountant ziet er op toe dat met alle aanwezige vormen van belastinglatenties rekening wordt gehouden en dat ze toegepast worden overeenkomstig de richtlijnen voor de jaarverslaggeving.

Hij dient derhalve vast te stellen dat de belastinglatenties overeenstemmen met de verschillen tussen de jaarrekening en de voorlopige fiscale balans. Tevens moet hij beoordelen of in voorkomende gevallen terecht saldering van actieve en passieve belastinglatenties is toegepast.

Ook hier geldt dat de ervaring en informatie over voorgaande fiscale jaarstukken en belastingaangiften enerzijds en de jaarrekeningen anderzijds richtinggevend zijn voor de oordeelvorming van de accountant. Daarnaast zal hij voor afwijkende standpunten en ontwikkelingen over het lopende boekjaar informatie moeten inwinnen bij de directie en diens belastingadviseur.

\section{De verantwoordelijkheid van de accountant voor belastingfraude}

\subsection{Inleiding}

Tot slot van dit artikel wordt aandacht besteed aan de verantwoordelijkheid van de openbare accountant voor het opsporen van belastingfraude en het melding maken van geconstateerde belastingfraude, indien de accountant jaarrekeningcontrole verricht.

In de praktijk is belastingfraude veelal een vorm van directiefraude; zij heeft meestal (grote) gevolgen voor de vennootschapsbelasting. Redenen waarom de behandeling van het onderwerp binnen deze kaders behandeld wordt, hetgeen overigens zal gebeuren aan de hand van twee praktijkproblemen.
Voor definiëring van het begrip belastingfraude zoek ik aansluiting bij de visie van collega Blokdijk:

Onder belastingfraude wordt verstaan

a de onrechtmatige onttrekking aan de huishouding door de directie, gepaard gaande met een poging de onrechtmatigheid van de onttrekking te verhullen (verder aangeduid als: onrechtmatige onttrekking), of

b de bewuste onjuiste voorstelling van feitelijkheden in de belastingaangifte door de leiding van de huishouding (verder aangeduid als misleiding).

\subsection{Onrechtmatige onttrekking}

In de praktijk is veelal sprake van belastingfraude in de vorm van onrechtmatige onttrekking, indien de directeur-grootaandeelhouder zich gelden toeëigent, die onttrokken worden aan de opbrengstverantwoording.

Hoewel dit in de praktijk vaak zal voorkomen in situaties waarin er sprake is van onvoldoende functiescheiding is dit voor de verantwoordelijkheid voor het ontdekken ervan in beginsel niet relevant.

De accountant zal dan ook de opbrengstenverantwoording en de daarmee samenhangende goederen- en geldbeweging controleren op basis van een controleprogramma, zoals hij dit normaal tijdens een jaarrekeningcontrole uitvoert. Dit is bepalend voor zijn verantwoordelijkheid.

Aangezien zijn controleprogramma mede wordt bepaald door het inherent risk en het control risk, zullen indicaties als fraudegevoelige branche, grote kasstromen en een zwakke $\mathrm{AO} / \mathrm{IC}$ van invloed zijn op zijn controleprogramma.

In het geval dat er sprake is van een directeur grootaandeelhouder zal het maken van een vermogensvergelijking te zijnen aanzien aanvullende informatie en zekerheid aan de accountant kunnen verschaffen. Dit laatste behoort evenwel vaak niet tot de mogelijkheden van de openbare accountant.

\subsection{Misleiding}

De tweede vorm van belastingfraude is mislei- 
ding. Deze manifesteert zich veelal in de twee volgende vormen.

1 Valse kosten- en inkoopfacturen.

-2 De oprichting van gelieerde ondernemingen in zogenaamde belastingparadijzen.

Gezien het belang voor de accountant en voor de beeldvorming blijft de behandeling van dit onderwerp beperkt tot de tweede vorm.

In een situatie waarin een onderneming internationaal opereert, zal zij de neiging hebben de winst en daarmede de belastingheffing zodanig over verschillende landen te verdelen, dat zij zo min mogelijk belasting betaalt. Dit is niet alleen op zich legaal, maar ook in overeenstemming met economische doelstellingen.

Voorwaarde is evenwel dat de internationale constructie de reële commerciële bedrijfsverhoudingen weerspiegelen.

Indien dit niet het geval is, is er sprake van belastingfraude, omdat door een schijnconstructie de winst die de Nederlandse vestiging op grond van haar activiteiten toekomt voor een deel ten onrechte neervalt in het buitenland, waar een lager belastingtarief geldt.

Dit te beoordelen is een normale controleactiviteit in het kader van de jaarrekeningcontrole, omdat hiermee samenhangt de beoordeling van de belastingdruk en de belastingschuld.

Voor het beoordelen van de aanvaardbaarheid van de intercompany-verhoudingen moet de accountant dan ook een aantal vragen beantwoorden, zoals:

1 Wat is de achtergrond van de oprichting van het buitenlandse lichaam?

2 Is het buitenlands gelieerd lichaam feitelijk buiten het Rijk gevestigd?

Indicaties hiervoor zijn:

- plaats van de centrale leiding (feitelijke beleidsbeslissingen);

- plaats van de administratie;

- plaats van de ondernemingsuitoefening.

3 Welke activiteit verricht het buitenlands lichaam (inkoop, verkoop, opslag, enzovoort)? Is er een profit center?

4 Heeft het buitenlands lichaam substance? (postbusmaatschappij, aantal personeelsleden, feitelijke afsluiting inkoop- respectievelijk verkooporders, feitelijke goederenrouting).

5 Is er sprake van feitelijke belastingplicht naar de winst in het buitenland?

6 Zijn de intercompanyprijzen aanvaardbaar? (beoordeling kostprijscalculaties, marktprijzen, verkoopprijzen aan derden, inkoopprijzen van derden).

7 Is de winst die in het buitenland valt in een redelijke verhouding tot de in dat buitenland vervulde bedrijfsfunctie en tot de gelopen en te lopen bedrijfsrisico's?

Indien een of meerdere vragen met neen beantwoord worden, moet de accountant de mogelijkheid onder ogen zien, dat er sprake is van belastingfraude door misleiding; hij moet dan ook een diepgaander onderzoek instellen.

Komt de accountant tot de conclusie dat er naar de Nederlandse fiscus toe sprake is van misleiding dan dient hij met het effect hiervan op de belastingverplichting rekening te houden.

De accountant kan echter geconfronteerd worden met het feit dat hij een aantal van bovengenoemde vragen niet kan beantwoorden, dan wel niet beantwoord krijgt, bijvoorbeeld omdat hij geen toegang heeft tot de administratie van de buitenlandse vennootschap.

In die situatie zal de accountant moeten afzien van een goedkeurende verklaring zonder voorbehoud en zal de hieruit voortvloeiende onzekerheid - afhankelijk van de materialiteit van de buitenlandse vennootschap - moeten leiden tot een goedkeurende verklaring onder voorbehoud dan wel tot een verklaring van oordeelonthouding.

\subsection{Verantwoordelijkheid voor het ontdekken van belastingfraude}

De accountant is niet verantwoordelijk voor het ontdekken van belastingfraude in het kader van zijn jaarrekeningcontrole, indien

1 de belastingfraude in omvang blijft binnen de toelaatbare foutentolerantie ten aanzien van de verantwoording als geheel, dan wel van de deelcontrole-objecten waarop de fraude direct betrekking heeft (non-material fraude);

2 de belastingfraude valt onder het axiomatisch 


\section{MAB}

voorbehoud, indien het niet-ontdekken niet het gevolg is van leemtes en tekortkomingen in het controleprogramma en de uitvoering ervan, zoals bijvoorbeeld in de volgende situaties:

a er is sprake van evenwichtige onvolledigheden in de goederen en bijbehorende geldbeweging;

b er is sprake van samenspanning;

c er wordt misleidende informatie verstrekt, waaronder valse bescheiden;

$\mathrm{d}$ in het kader van de kosten-batenanalyse van de controle vindt beperking van de controlehandelingen plaats (met name sampling risk).

\subsection{Verantwoordelijkheid voor het melden van belastingfraude}

Indien de accountant belastingfraude ontdekt, dient hij primair bij zich zelf te rade te gaan, of hij bij deze onderneming nog wel kan functioneren en zijn controle-opdracht niet moet teruggeven. In ieder geval zal hij de ondernemingsleiding en het toezichthoudend orgaan schriftelijk in kennis moeten stellen van zijn bevindingen en aanbevelingen doen tot het herstellen van de gevolgen van die fraude.

Werkt de ondernemingsleiding hieraan niet mee dan staat de accountant (al dan niet cumulatief) het volgende te doen:

a Teruggeven van de controle-opdracht

Het teruggeven van de controle-opdracht is geboden, omdat de vertrouwensrelatie tussen accountant en ondernemingsleiding ernstig wordt aangetast, indien de ondernemingsleiding zich inlaat met het plegen van belastingfraude, zijnde een ernstig strafbaar feit.

b Zelfstandig mededelingen te doen binnen het gestelde in artikel 10, lid 4 GBR onder intrekking van de accountantsverklaring, indien de belastingfraude betrekking heeft op een afgelopen boekjaar.

Het zelfstandig mededelingen doen moet gezien worden in het kader van gebeurtenissen na balansdatum en in relatie tot de goede trouw van de ondernemingsleiding. Omdat gepleegde belastingfraude naar zijn aard en veelal ook in omvang materieel is, moet dan ook gesteld worden, dat 'nadien gebleken is dat de jaarrekening in ernstige mate tekort schiet in het geven van het vereiste inzicht', terwijl er voorts in het algemeen sprake zal zijn van het ontbreken van goede trouw.

c Aan de rechter in belasting- en/of strafzaken de door hem gewenste informatie verschaffen, indien de accountant als getuige gehoord wordt.

De reikwijdte van de uitspraken van de Hoge Raad in een civiele (25-10-1983) en een strafrechtelijke (6-5-1986) procedure brengen analoog met zich mee dat de openbare accountant als getuige ook in belastingprocedures geen verschoningsrecht toekomt.

Immers ook in belastingzaken geldt dat het algemeen belang van de waarheidsvinding en dus van het maatschappelijk verkeer, zwaarder weegt dan de geheimhoudingsplicht van de accountant ten opzichte van de ondernemingsleiding, ofwel dan het individueel belang.

d Overwegen of in de betreffende situatie het belang van zijn algemene functie als vertrouwensman van het maatschappelijk verkeer niet zwaarder weegt dan zijn geheimhoudingsplicht, zodat hij zelfstandig melding maakt van de belastingfraude. Dit geldt in ieder geval naar de fiscus toe, indien hem daarnaar gevraagd wordt en wel op grond van zijn meldingsplicht die voortvloeit uit artikel 49, lid 3 Algemene Wet Rijksbelastingen.

Maar ook in algemene zin, te weten naar de Officier van Justitie toe, moet meldingsplicht niet uitgesloten worden als behorende tot de verantwoordelijkheid van de openbare accountant.

Met name deze laatste stelling kan als discutabel ervaren worden. De ontwikkelingen in het verwachtingspatroon van het maatschappelijk verkeer lijken evenwel in de richting te gaan, dat het accountantsberoep zich terdege moet afvragen, of het zijn algemene functie adequaat kan blijven vervullen zonder aan die behoefte te voldoen. 